\title{
JUURNAL_RU
}

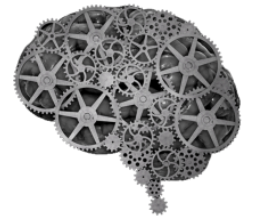

COMPANY GROUP "INTELLEKT"

Бондарь С.C. Тульский государственный университет Тула, Россия

doi: 10.18411/1j2016-3-07

\section{Использование активной радиометрии для визуализации результатов лечения пациентов с внебольничной пневмонией}

В настоящее время одной из актуальных задач медицины является повышение информативности диагностических вмешательств [1]. При этом целесообразно внедрение в клинику новых информативных методов диагностики, а так же повышение чувствительности и специфичности уже использующихся. Одной из перспективных диагностических технологий для использования в клинике внутренних болезней, является активная радиометрия (AР) [2]. Показано, что АР является высокочувствительным к изменениям сосудистой проницаемости и активности метаболизма диагностическим методом, который может применяться с целью дифференциальной диагностики ряда заболеваний внутренних органов [3-13] и их функционального состояния [14].

Цель исследования - изучение возможности активной радиометрии в визуализации результатов лечения пациентов с нетяжелой внебольничной пневмонией.

Материалы и методы. На клинической базе кафедры-клиники терапии Саратовского военно-медицинского института проведено проспективное, контролируемое двойное слепое клиническое исследование в котором методом активной радиометрии (АР) обследовано 15 пациентов мужского пола с 
внебольничной бактериальной пневмонией (ВП) в стадии разрешения (15-18 сутки заболевания). АР проводилась с помощью радиоэлектронного комплекса «Аквафон» (регистрационное удостоверение ФСР 2010/07292) [2, 15].

Критерием оценки результатов исследования являлся показатель «радиоотклик» - РО, представляющий собой сумму амплитуд радиоизлучения, зарегистрированного с анатомо-топографической области [2]. Статистический анализ проводился в программе Statistica 6.0. Оценка значимости межгрупповых различий проводилась методом однофакторного дисперсионного анализа (ANOVA).

Результаты и обсуждение. Результаты анализа представлены в таблице.

Таблица

Уровень показателей ВА (ед.) в динамике ВП $(M+\sigma)$

\begin{tabular}{|c|c|c|c|c|c|}
\hline \multirow{2}{*}{ Форма ВП } & \multirow{2}{*}{ Сторона } & \multicolumn{4}{|c|}{ Сутки заболевания } \\
\hline & & 1 & 7 & 20 & Контроль \\
\hline \multirow{2}{*}{$\begin{array}{c}\text { Нетяжелая } \\
\text { ВП }\end{array}$} & $\begin{array}{c}\text { Сторона } \\
\text { поражения }\end{array}$ & $137 \pm 3,5^{*}$ & $119,4 \pm 1,7^{*}$ & $115,1 \pm 1,3$ & \multirow{2}{*}{$93,3 \pm 2,5$} \\
\hline & $\begin{array}{c}\text { «Здоровая» } \\
\text { сторона }\end{array}$ & $122,1 \pm 2,7^{*}$ & $107,3 \pm 1,1$ & $110,5 \pm 1,2$ & \\
\hline
\end{tabular}

* - различие статистически значимо в сравнении с контролем.

Результаты исследования свидетельствуют о статистически значимых различиях уровня $\mathrm{PO}$ на стороне поражения и противоположной «здоровой» стороне, а так же у пациентов с ВП и группой контроля. Кроме того, проведенный анализ показал, что существенные различия РО в сравнении с группой контроля на стороне поражения сохраняются в течение 20 дней, а на противоположной стороне поражения - в течение недели.

На рисунке представлены диагностические изображения, полученные в процессе проведения АР пациенту с левосторонней нижнедолевой ВП на 1-е 
(стадия разгара ВП), 7-е (стадия разрешения ВП) и 20-е сутки (реконвалесценция ВП).

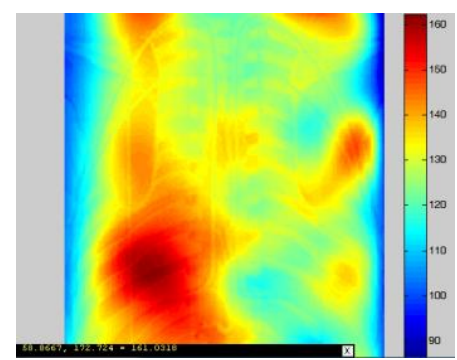

1-е сутки ВП

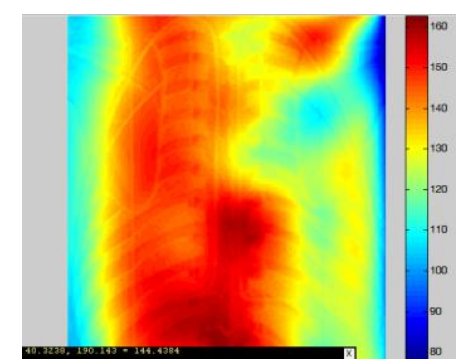

7-е сутки ВП

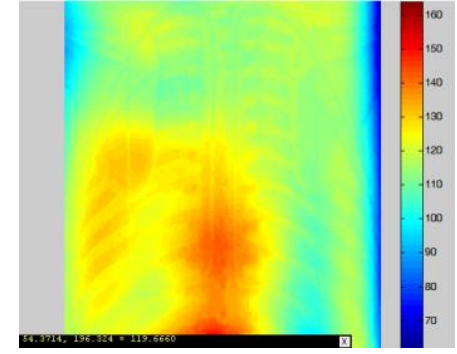

20-е сутки ВП

Рис. Динамика радиометрических изменений в процессе лечения ВП

Проведенный анализ карт распределения радиосигнала по грудной клетке показал, что в первые сутки ВП имеет место значительное повышение ВА в проекции патологического очага (ВА слева 161,0 ед., справа 124,3 ед.). В проекции корня на стороне поражения так же регистрируется повышенный уровень ВА (слева - 127,2 ед., справа - 117,5 ед.). На 7-е сутки ВП, в проекции инфильтрированных сегментов ВА - 144,4 ед., в проекции корня - 127,1 ед. На 20-е сутки ВП, в проекции инфильтрированных сегментов ВА - 119,6 ед., в проекции левого корня - 113,1 ед., на противоположной стороне - 109,3 ед.

Заключение. Результаты исследования свидетельствуют о возможности объективизации картины распределения сосудистой проницаемости в легком методом АР $[15,16]$. Визуальное представление распределения интенсивности излучения по области интереса позволяет проводить мониторинг эффективности лечебных мероприятий у таких больных [17-19]. 


\section{Литература:}

1. Избранные технологии диагностики: Монография / В.М. Еськов и др.; под ред. А.А. Хадарцева, В.Г. Зилова, Н.А. Фудина. Тула: ООО РИФ «ИНФРА», 2008. $296 \mathrm{c}$.

2. Терехов И.В. Транс-резонансная функциональная топография в диагностике заболеваний органов дыхания (новый метод обработки информации): автореф. дисс. канд. мед. наук. Тула, 2007. 24 с.

3. Применение метода ТРФ-топографии в диагностике воспалительных изменений нижних отделов респираторного тракта / Терехов И.В., Громов М.С., Парфенюк В.К. и др. // Саратовский научно-медицинский журнал. 2008. T. 4. № 1. C. 79-83.

4. Возможность использования активной СВЧ-радиометрии для оценки альвеолярно-капиллярной проницаемости в эксперименте / Терехов И.В., Солодухин К.А., Аржников В.В. и др. // Регионарное кровообращение и микроциркуляция. 2011. Т. 10. № 4. С. 83-86.

5. Терехов И.В., Дзюба М.А., Наджарьян Л.С. Оценка альвеолярнокапиллярных нарушений при развитии тяжелого гемодинамического отека легких у крыс и их коррекция с помощью СВЧ-излучения // Саратовский научно-медицинский журнал. 2011. Т. 7. № 2. С. 389-392.

6. Применение транс-резонансной функциональной топографии с целью оптимизации диагностической тактики у пациентов с подозрением на острый панкреатит и его осложнения / Лобаков А.И., Громов М.С., Дубовицкий С.А., Тер-Симонян Г.В., Терехов И.В. и др. // Хирург. 2008. № 8. С. 22-33.

7. Трансрезонансная функциональная топография в оптимизации диагностики у пациентов с подозрением на острую воспалительную патологию органов брюшной полости / Громов М.С., Масляков В.В., Брызгунов А.В., Терехов И.В. и др. // Анналы хирургии. 2008. № 6. С. 60-63.

8. Идентификация и дифференциация костных новообразований методом активной радиометрии / Незнамов М.Н., Зайцев В.А., Ругина Н.А., Бондарь 
С.С., Терехов И.В. // Вестник новых медицинских технологий. Электронное издание. 2015. Т. 9. № 2. С. 20.

9. Использование радиоволнового зондирования водосодержащих сред миокарда у больных с артериальной гипертензией / Терехов И.В., Солодухин К.А., Никифоров В.С., Ломоносов А.В. // Российский кардиологический журнал. 2013. № 5 (103). С. 40-43.

10. Терехов И.В., Логаткина А.В., Бондарь С.С. Функциональное состояние миокарда и его связь с состоянием водосодержащих сред органов грудной клетки при инфильтративных процессах в легких // Stredoevropsky Vestnik pro Vedu a Vyzkum. 2015. T. 51. C. 3.

11. Терехов И.В., Парфенюк В.К. Мониторинг инфильтративных процессов нижних отделов респираторного тракта у пациентов с внебольничной пневмонией методом люминесцентного анализа в радиодиапазоне // Вестник восстановительной медицины. 2009. № 3. С. 46-50.

12. Интегральная оценка воспалительного процесса у больных внебольничной пневмонией методом активной радиометрии / В.В. Аржников, В.Б. Лифшиц, В.К. Парфенюк, И.В. Терехов // Саратовский научно-медицинский журнал. 2011. T. 7. № 4. C. 817-822.

13. Громов М.С., Терехов И.В. Характеристика системного воспалительного ответа у больных внебольничной пневмонией в динамике при помощи активной СВЧ-радиометрии // Казанский медицинский журнал. 2010. Т. 91. № 5. С. 611-614.

14. Громов М.С., Аржников В.В., Терехов И.В. Возможности оценки функционального состояния организма с помощью собственного радиоизлучения нетепловой природы // Медицинский вестник МВД. 2008. № 5 (36). C. 38-43.

15. Дифференциальная диагностика заболеваний грудной клетки с помощью транс-резонансной функциональной топографии / Терехов И.В., Петросян 
В.И., Громов М.С., Масляков В.В. и др. // Вестник медицинского института "РЕАВИЗ": реабилитация, врач и здоровье. 2013. № 3 (11). С. 18-26.

16. Диагностика и мониторинг инфильтративных процессов в грудной полости с помощью люминесцентного излучения водосодержащих сред / Аржников В.В., Терехов И.В., Громов М.С. // Медицинский вестник МВД. 2009. № 2 (39). C. 40-46.

17. Терехов И.В. Оценка сосудистой проницаемости с помощью активной радиометрии // Аспирантский вестник Поволжья. 2009. № 7-8. С. 187-190.

18. Технология динамической оценки воспалительного процесса с помощью активной резонансной радиометрии / Терехов И.В., Громов М.С., Петросян В.И., Бондарь С.С. и др. // Вестник новых медицинских технологий. 2010. Т. 17. № 1. C. 135-137.

19. Дифференциация инфильтративных изменений в легких с помощью топографического картирования СВЧ-излучения органов грудной полости / Громов М.С., Терехов И.В., Бондарь С.С., Дзюба М.А., Аржников В.В. // Вестник новых медицинских технологий. 2010. Т. 17. № 3. С. 208-211. 